\title{
Drag Characteristics for Optimally Span-loaded Planar, Wingletted, and C-wings
}

\author{
Ronald Slingerland* and Joram G. Verstraeten ${ }^{\dagger}$ \\ Delft University of Technology, Delft, The Netherlands
}

\begin{abstract}
This paper focuses on the drag characteristics of optimally span-loaded planar, wingletted, and C-wings. The span-load is optimized resulting in minimum induced or total drag. The wing-root bending moment is kept constant for all analyzed wings to ascertain different wings have comparable weight. The optimum span-loadings for the different types of wing are calculated using a fast and simple numerical method. The wings are analyzed in the Trefftz-plane, infinitely far behind the wing. Lagrange multipliers are used to calculate the optimum span-loading resulting in minimum induced or total drag, with the wing-root bending moment and/or the lift coefficient as constraint. The induced drag can be calculated using the optimum span-loading. The profile drag is assumed to be a function of the local lift coefficient. The results indicate that the $\mathrm{C}$-wing does not have real aerodynamic performance advantages compared to a wingletted wing. For wings with span and/or aspect ratio constraints a winglet offers a drag reduction relative to a planar wing.
\end{abstract}

\section{Nomenclature}

$A_{i j} \quad$ Geometric influence function

$b \quad$ Wingspan, $\mathrm{m}$

$C_{D} \quad$ Total drag coefficient

$C_{D_{i}} \quad$ Induced drag coefficient

$C_{L} \quad$ Lift coefficient

$C_{M} \quad$ Wing-root bending moment coefficient

$c \quad$ Chord, $\mathrm{m}$

$\bar{c} \quad$ Mean geometric chord, $\mathrm{m}$

$c_{d_{0}}, c_{d_{2}} \quad$ Profile drag coefficients

$c_{d_{p}} \quad$ Local profile drag coefficient

$c_{n} \quad$ Local normal force coefficient

$J \quad$ Goal function

L Lift, N

$l \quad$ Surface length or height, $\mathrm{m}$

$M, N \quad$ Number of horseshoe vortices

$M_{b} \quad$ Wing-root bending moment, $\mathrm{N}$

$q_{\infty} \quad$ Dynamic pressure, $\mathrm{N} / \mathrm{m}^{2}$

$S \quad$ Wing area, $\mathrm{m}^{2}$

$s \quad$ Nondimensional semi-width of a vortex pair

$V \quad$ Flow velocity, $\mathrm{m} / \mathrm{s}$

$V_{n} \quad$ Normal velocity, $\mathrm{m} / \mathrm{s}$

$v \quad$ Velocity component in the $\mathrm{y}$-plane, $\mathrm{m} / \mathrm{s}$

$w \quad$ Velocity component in the z-plane, downwash, $\mathrm{m} / \mathrm{s}$

${ }^{*}$ Deceased October 19, 2007. Former Assistant Professor, Faculty of Aerospace Engineering Department Design, Integration and Operation of Aircraft and Rotorcraft, Kluyverweg 1, 2629 HS, Delft, the Netherlands, Former Member AIAA.

†Student, Faculty of Aerospace Engineering, Department Design, Integration and Operation of Aircraft and Rotorcraft, Kluyverweg 1, 2629 HS, Delft, the Netherlands. 


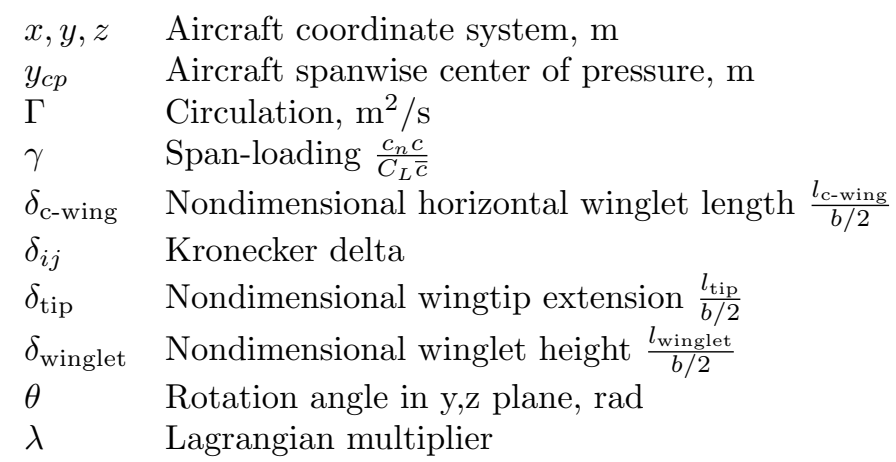

Subscript

$i, j \quad$ Number designating a vortex pair that models a particular lifting element

\section{Introduction}

One of the reasons it takes energy to fly from one point to another is the presence of drag. The drag of a subsonic transport aircraft during cruise consists mainly of profile drag and induced drag. This paper focuses on the reduction of induced drag. Induced drag is the drag due to the creation of lift. Reducing the induced drag reduces fuel use, gas emissions, and noise emissions. One successful innovation in aircraft aerodynamic design of the last decades is the winglet. A winglet is the often seen vertical surface at the tip of the wing. Its purpose is the reduction of induced drag. A frontal view of both a planar and wingletted wing is given in figs. $1(\mathrm{a})$ and $1(\mathrm{~b})$.

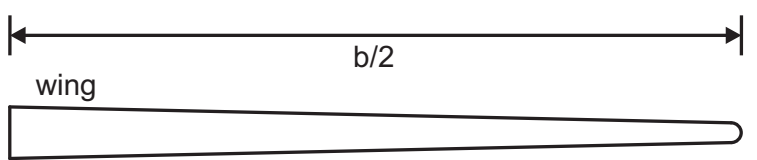

(a) planar wing

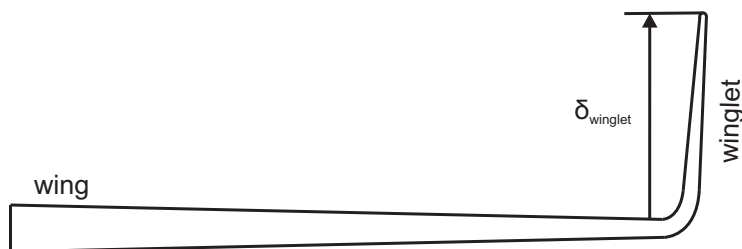

(b) wingletted wing

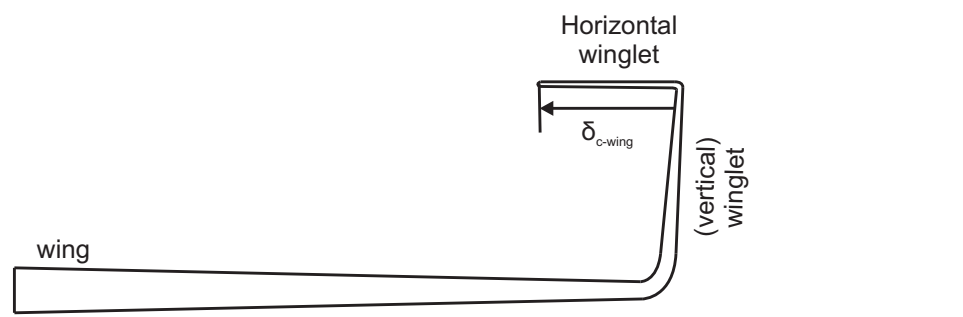

(c) C-wing

Figure 1. Frontal view of planar, wingletted, and C-wing. Wing semi-span $\frac{b}{2}$ indicated. Nondimensional winglet height $\delta_{\text {winglet }}$ and length $\delta_{c-\text { wing }}$ indicated. $\delta=1$ equals the wing semi-span.

This study was initially undertaken to investigate the opportunities of the C-wing and present the possible benefits associated with it. Inspired by the winglet, the $\mathrm{C}$-wing has both horizontal and vertical winglets. A frontal view of a $\mathrm{C}$-wing is given in fig. 1(c). It soon turned out however that the aerodynamic advantages of the $\mathrm{C}$-wing are negligible, for reasons explained in this paper. Luckily, the field of winglets is also well worth studying. The many different designs seen on today's aircraft show that there is no real consensus regarding the optimal design of winglets. There is no consensus even regarding the question if a winglet is favorable compared to another classic way of reducing induced drag, namely increasing the wingspan. Therefore the 
main goal of this study is to find out if there are clear benefits to winglets as opposed to a simple wingtip extension.

The numerical method used in this study to analyze wings is simple and fast. It models the wing in the Trefftz-plane infinitely far behind the wing, making it possible to study many different wing configurations and get a global idea how they perform relative to each other. This way C-wings with many different dimensions can be compared to winglets of different height. Furthermore the wingletted wings can be compared to planar wings of varying span. It should be noted that the method used in this paper calculates theoretical optimum loadings resulting in minimum induced or total drag. The calculated loading must be obtained by using the right amount of aerodynamic and geometric twist. Because of the complexity of a wing this loading can probably only be approximated in real-life. Furthermore, the results are not valid for retro-fitted winglets because the twist of the wing is fixed.

Although the results may not be as precise as obtained with for example computational fluid dynamics (CFD), it is possible to take the first steps into finding an optimal configuration, especially optimal winglet length and optimal $\mathrm{C}$-wing dimensions. The optimal configuration aimed for in this paper is the configuration resulting in minimum total drag for a wing with a given lift and wing-root bending moment. If that configuration is known, CFD or other more sophisticated tools can still be used to further optimize the chosen configuration.

\section{Analysis}

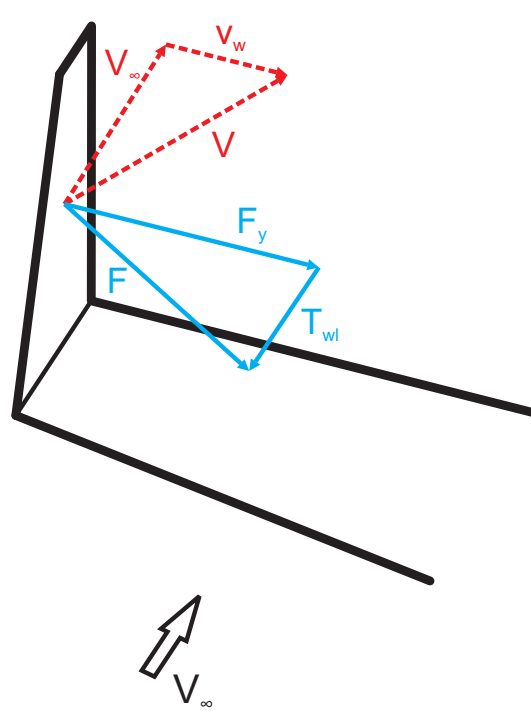

(a) Influence of wing on winglet

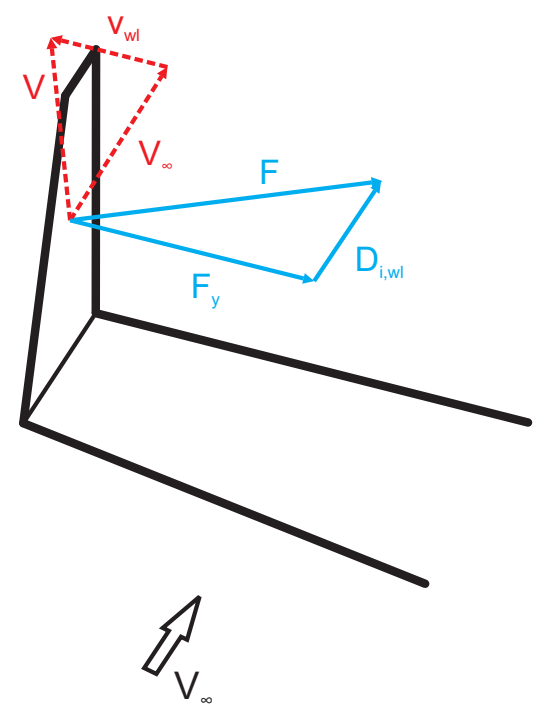

(b) Creation of induced drag by the winglet itself

Figure 2. Influence of wing on winglet and of the winglet on itself. The dashed red arrows indicate velocities and the solid blue arrows indicate forces.

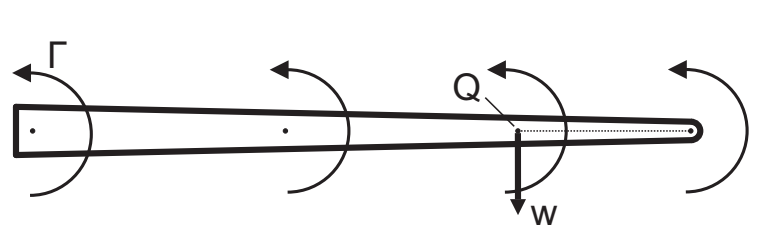

(a)

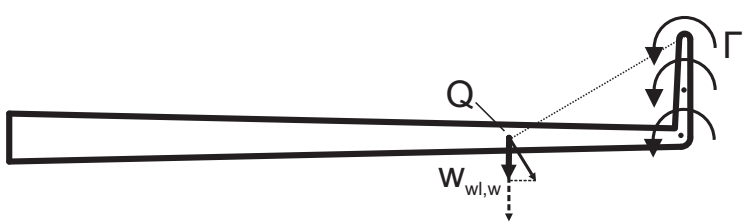

(b)

Figure 3. Influence of a winglet on the wing. 


\section{A. Physical analysis of nonplanar wings}

The basic physical effect of winglets and C-wings is the diffusion of the vortex flow just downstream of the wing. ${ }^{1}$ The mechanism by which the drag reduction due to a winglet is accomplished is twofold. A properly designed winglet creates a sideforce $F$, which is inclined forward due to an inward deflection of the airflow $V$, as can be seen in fig. 2(a). This deflection is caused by the flow component $v_{w}$ due to the pressure difference between the lower and upper surface of the wing at the wingtip. The resulting thrust component $T_{w l}$ reduces the induced drag. As can be seen in fig. 2(b) the winglet itself also creates an induced drag component $D_{i_{w l}}$ due to the sidewash $v_{w l}$ created by the winglet. For an optimally loaded wing with vertical winglets this induced drag exactly cancels out the thrust component according to Munk's third theorem. Munk's third theorem states that the induced drag is minimum when the following relation is satisfied ${ }^{2}$

$$
V_{n}=w \cos \theta
$$

The theorem implies that the induced drag will be minimum when the induced velocity normal to the lifting element $V_{n}$ at each point is equal to the downwash $w$ times the cosine of the angle of inclination $\theta$ of the lifting ele-

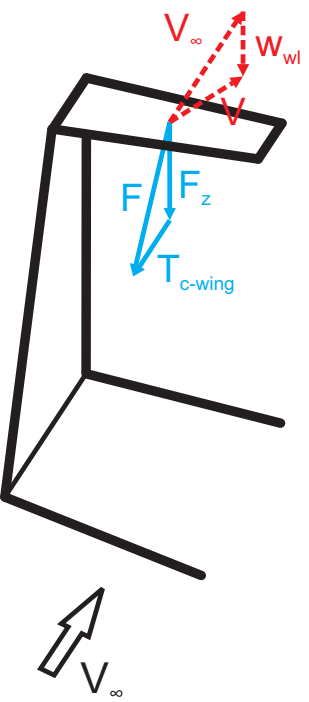

Figure 4. Influence of winglet on horizontal winglet of a $\mathrm{C}$-wing. The dashed red arrows indicate velocities and the solid blue arrows indicate forces. ment at that point. For a vertical winglet $\left(90^{\circ}\right.$ inclination) this implies that the induced normal velocity at the winglet is zero, and hence the drag component $D_{i_{w l}}$ will cancel the thrust component $T_{w l}$ out. Optimally loaded vertical winglets do however reduce induced drag due to a second mechanism of drag reduction.

The second mechanism by which the induced drag is reduced is a decrease in downwash of the flow approaching the wing due to the winglet. The winglet influences the flow over the wing. Figure 3(a) shows a wing without winglet. It also shows the circulation $\Gamma$ in a schematic way. Using the Biot-Savart ${ }^{\mathrm{a}}$ law the induced velocity can be related to circulation strength and distribution. The law basically shows that the induced velocity is proportional to the circulation strength and inversely proportional to the distance. Now consider point $\mathrm{Q}$ in figure 3(a). Here the downwash $w$ caused by the circulation of the tip is indicated by the arrow. Figure 3(b) shows a wing with winglet. The circulation at the tip is now spread over the winglet. This has two effects. The induced velocity is now under a varying angle relative to the downwash of the planar wing and the distance to point $\mathrm{Q}$ is increased. Both effects cause a decrease in downwash, and hence a decrease of induced drag.

The above is also valid for the $\mathrm{C}$-wing. Additionally, the horizontal surface of the $\mathrm{C}$-wing acts as a winglet for the vertical winglet. This implies that the load on the additional horizontal surface of the C-wing needs to be orientated downward. This load is tilted forward under the influence of the flow component $w_{w l}$ caused by the pressure difference at the vertical winglet tip, creating a thrust component $T_{c-w i n g}$, see fig. 4 .

\section{B. Numerical method to calculate optimum span-loading}

This study makes use of a numerical method to calculate the induced drag for an arbitrary span-loading or the optimum span-loading which results in minimum induced drag for arbitrary nonplanar aircraft. ${ }^{2}$ The aircraft lifting surfaces are represented by a system of rectangular horseshoe vortices. Utilizing this vortex representation and Munk's three theorems, the Biot-Savart Law, and the Kutta-Joukowski theorem ${ }^{\mathrm{b}}$ the induced drag for a given loading or the optimum loading for minimum induced drag can be calculated. This study concentrates on finding the optimum loading for several wing configurations.

\footnotetext{
${ }^{a}$ The Biot-Savart law is given in the appendix

${ }^{\mathrm{b}}$ The Kutta-Joukowski theorem is given in the appendix
} 


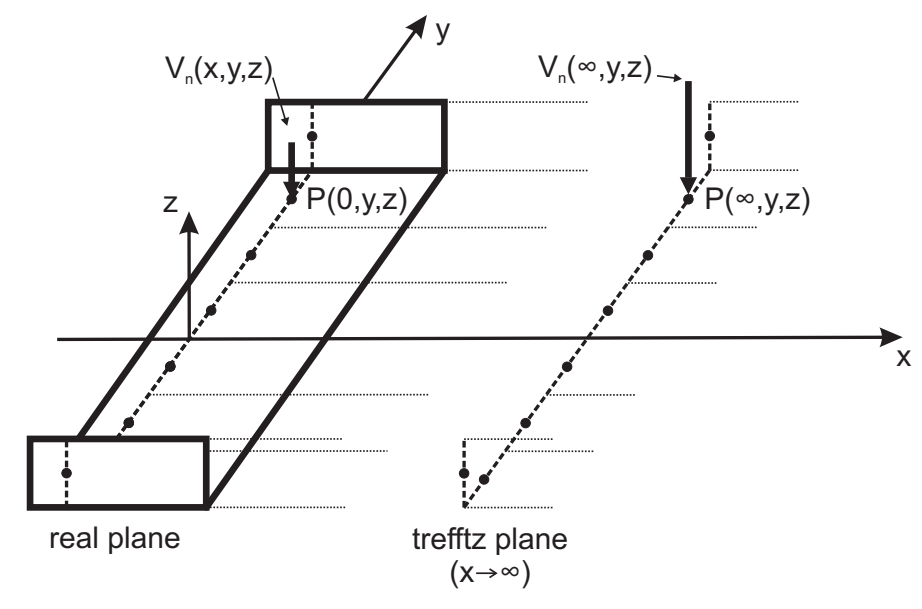

Figure 5. Illustration of Munk's first and second theorem. ${ }^{2}$ The aircraft lifting surfaces are represented by a system of rectangular horseshoe vortices.

Munk's first theorem allows all forces of the wing to be concentrated in the Y,Z-plane, as is indicated by the dotted line over the wing in fig. 5. Munk's second theorem allows the computations to be done in the Trefftz-plane at downstream infinity, rather than in the real plane which reduces the number of parameters used and simplifies the calculations. According to the second theorem the normal velocity calculated in the Trefftz-plane at a control point $P(\infty, y, z)$ is twice the actual value of the normal velocity in the corresponding control point $P(0, y, z)$ in the real plane.

In the real plane the aircraft lifting surfaces are represented by a system of horseshoe vortices. This is schematized in fig. 5. The induced velocities in the Trefftz-plane at a control point $P\left(\infty, y_{i}, z_{i}\right)$ due to a horseshoe vortex located in the real plane at point $P\left(x_{j}, y_{j}, z_{j}\right)$ can be derived from the Biot-Savart law. The induced velocities are functions of the circulation and wing geometry. With the Kutta-Joukowski theorem the circulation can be written in terms of span-loading $\left(\frac{c_{n} c}{\bar{c}}\right)$. Since the induced $\operatorname{drag} \operatorname{coefficient} C_{D_{i}}$ is a function of the induced velocities, the induced drag coefficient can be obtained in terms of span-loading and wing geometry. The lift coefficient $C_{L}$ can also be written as a function of span-loading and wing geometry

$$
\begin{gathered}
C_{D_{i}}=\sum_{i=1}^{N} \sum_{j=1}^{N} \frac{\left(c_{n} c\right)_{i}}{\bar{c}} \frac{\left(c_{n} c\right)_{j}}{\bar{c}} s_{i} A_{i j} \\
C_{L}=2 \sum_{j=1}^{N} \frac{\left(c_{n} c\right)_{j}}{\bar{c}} s_{j} \cos \theta_{j}
\end{gathered}
$$

$s, A$, and $\theta$ are functions of the wing geometry of the aircraft. ${ }^{2}$ The span-loading $\frac{c_{n} c}{\bar{c}}$ is the parameter that is optimized for minimum drag. $c_{n}$ is the section load coefficient normal to the projection of the aircraft lifting surfaces in the Trefftz-plane parallel to the YZ-plane. When using the Trefftz-plane it is assumed that the wake extends infinitely far downstream and trails back from the wing in the freestream direction. Therefore $c_{n}$ equals the local lift coefficient $c_{l}$ for a horizontal wing segment.

\section{Optimum span-loading resulting in minimum induced drag}

To find the optimum span-loading resulting in minimum induced drag Lagrange multipliers are used. ${ }^{3}$ A goal function is formulated containing the function that needs to be optimized and the constraints. The most basic goal function optimizes for minimum induced drag with the lift coefficient as constraint. The goal function in such a case is

$$
J=C_{D_{i}}+\lambda\left(C_{L}-C_{L_{i n p}}\right)
$$


$C_{D_{i}}$ and $C_{L}$ follow from (2) and (3). $C_{L_{i n p}}$ is the desired lift coefficient, and $\lambda$ is the Lagrange multiplier. The condition for minimum induced drag can be expressed by the following equation

$$
\left[\begin{array}{c}
\frac{\partial J}{\partial \gamma_{i}} \\
\frac{\partial J}{\partial \lambda}
\end{array}\right]=\left[\begin{array}{l}
0
\end{array}\right] \quad \text { where } \quad \gamma_{i}=\frac{\left(c_{n} c\right)_{i}}{\bar{c}}
$$

Solving these differentiations yields a system of equations. This system can be solved to obtain a vector containing the optimum loading and as final entry the Lagrange Multiplier

$$
\left[\begin{array}{c}
\frac{\left(c_{n} c\right)_{i}}{\bar{c}} \\
\vdots \\
\hline \lambda
\end{array}\right]=\left[\begin{array}{c|c}
A_{i j} s_{i}+ & s_{i} \cos \theta_{i} \\
A_{i j}^{T} s_{j} & \vdots \\
\hline s_{j} \cos \theta_{j} \ldots & 0
\end{array}\right]^{-1}\left[\begin{array}{c}
0 \\
\vdots \\
\hline \frac{1}{2} C_{L_{i n p}}
\end{array}\right]
$$

The multiplier $\lambda$ is only a byproduct of this method and can be disregarded, ending up with the optimum span-loading that results in minimum induced drag for a certain lift coefficient.

\section{Wing-root bending moment constraint}

The wing-root bending moment is a good indicator of wing weight. By keeping the wing-root bending moment constant, it is assumed that wings of comparable weight are found and no iteration on lift is required. The wing-root bending moment $M_{b}$ is equal to the lift $L$ times the spanwise center-of-pressure location relative to the wing-root $y_{c p}$

$$
M_{b}=L y_{c p}
$$

The lift is a function of lift coefficient, dynamic pressure $q_{\infty}$, and wing area $S$

$$
L=C_{L} q_{\infty} S
$$

Both lift coefficient and wing area are input variables, so different wings with equal input create the same amount of lift at a certain dynamic pressure or speed. The center-of-pressure location is a function of the wing-root bending moment coefficient $C_{M}{ }^{2}$

$$
y_{c p}=\frac{2 b C_{M}}{C_{L}}
$$

Since the wing-root bending moment coefficient is also a function of span-loading and wing geometry it can be used as constraint in the model, thereby keeping the spanwise center-of-pressure location constant. The wing-root bending moment coefficient can be expressed as ${ }^{2}$

$$
C_{M}=\frac{1}{2} \sum_{j=1}^{N} \frac{\left(c_{n} c\right)_{j}}{\bar{c}} s\left(\frac{2 y_{j}}{b} \cos \theta_{j}+\frac{2 z_{j}}{b} \sin \theta_{j}\right)
$$

With this constraint, the lift coefficient constraint, and the wing area as input it is assured that the analyzed wings have the same wing-root bending moment, and hence comparable weight. With two different multipliers $\lambda_{C_{L}}$ and $\lambda_{C_{M}}$, and a moment coefficient input $C_{M_{i n p}}$, the new goal function becomes

$$
J=C_{D_{i}}+\lambda_{C_{L}}\left(C_{L}-C_{L_{i n p}}\right)+\lambda_{C_{M}}\left(C_{M}-C_{M_{i n p}}\right)
$$


The condition for minimum induced drag can be expressed by

$$
\left[\begin{array}{c}
\frac{\partial J}{\partial \gamma_{j}} \\
\frac{\partial J}{\partial \lambda_{C_{L}}} \\
\frac{\partial J}{\partial \lambda_{C_{M}}}
\end{array}\right]=[0] \quad \gamma_{j}=\frac{\left(c_{n} c\right)_{j}}{\bar{c}}
$$

Solving these differentiations yields a system of equations. This system can be solved to obtain a vector containing the optimum span-loading resulting in minimum induced drag with the lift and wing-root bending moment coefficient as constraints. The final two entries are the Lagrange multipliers, which can be disregarded.

$$
\left[\begin{array}{c}
\frac{\left(c_{n} c\right)_{j}}{\bar{c}} \\
\vdots \\
\vdots \\
\lambda_{C_{L}} \\
\lambda_{C_{M}}
\end{array}\right]=\left[\begin{array}{c|cc}
A_{i j} s+ & 2 s \cos \theta_{j} & s \frac{y_{j}}{b} \cos \theta_{j}+ \\
A_{i j}^{T} s & s \frac{z_{j}}{b} \sin \theta_{j} \\
& \vdots & \vdots \\
s \cos \theta_{i} \ldots & 0 & \\
s \frac{2 y_{i}}{b} \cos \theta_{i}+ & & \\
s \frac{2 z_{i}}{b} \sin \theta_{i} \ldots &
\end{array}\right]^{-1}\left[\begin{array}{c}
0 \\
\vdots \\
\vdots \\
\frac{1}{2} C_{L_{i n p}} \\
\\
2 C_{M_{i n p}}
\end{array}\right]
$$

\section{Optimum span-loading resulting in minimum total drag}

The wings can also be optimized for minimum total drag. The total drag is the induced drag plus the profile drag. It is assumed that the profile drag can be written as function of the local lift coefficient ${ }^{3}$ and therefore also as function of span-loading

$$
\begin{gathered}
c_{d_{p}}=c_{d_{0}}+c_{d_{2}} c_{n}^{2} \\
c_{d_{p}}=c_{d_{0}}+c_{d_{2}}\left(\frac{c_{n} c}{\bar{c}}\right)^{2}\left(\frac{\bar{c}}{c}\right)^{2}
\end{gathered}
$$

Where $c_{d_{p}}$ is the local profile drag coefficient, and $c_{d_{0}}$ and $c_{d_{2}}$ are constants. Equation (15) can be integrated over the wingspan and added to (2). Now a new goal function containing the total drag coefficient can be used to optimize for minimum total drag (for simplicity in explaining the method only the lift coefficient constraint is used)

$$
J=C_{D}+\lambda_{C_{L}}\left(C_{L}-C_{L_{i n p}}\right)
$$

Differentiating this goal function yields a system of equations. Solving this system one obtains a vector containing the optimum span-loading resulting in minimum total drag

$$
\begin{gathered}
{\left[\begin{array}{c}
\frac{\left(c_{n} c\right)_{j}}{\bar{c}} \\
\vdots \\
\hline \lambda_{C_{L}}
\end{array}\right]=\left[\begin{array}{c|c}
A_{i j} s+ & 2 s \cos \theta_{j} \\
A_{i j}^{T} s+D_{p} & \vdots \\
\hline s \cos \theta_{i} \ldots & 0
\end{array}\right]^{-1}\left[\begin{array}{c}
0 \\
\vdots \\
\hline \frac{1}{2} C_{L_{i n p}}
\end{array}\right]} \\
\text { where } D_{p}=4 \delta_{i j} s c_{d_{2}} \frac{\bar{c}}{c_{j}}
\end{gathered}
$$




\section{Results}

\section{A. Method verification}

To verify the method the results obtained for a planar wing using the current method are compared to the results obtained for such a wing by Prandtl. ${ }^{4}$ Figure 6 shows the span-load distribution (here divided by $C_{L}$, $\frac{c_{n} c}{C_{L} \bar{c}}$, and denoted in the graphs with $\gamma$ ) of a planar wing optimized for minimum induced drag, the result is an elliptical load distribution. The method used here only has a very small error with a magnitude that depends on the number of horseshoe vortices used per semi-span. In fig. 7 the number of vortices is plotted against the span efficiency factor $e$. The span efficiency factor of an elliptically loaded planar wing is 1 . For the right balance between speed and accuracy most of the calculations are done using 200 vortices per semi-span, resulting in an error of only $0.25 \%$. The additional surfaces of nonplanar wings use an equivalent number of vortices, e.g. a winglet with a height of $10 \%$ of the semi-span uses 20 vortices.

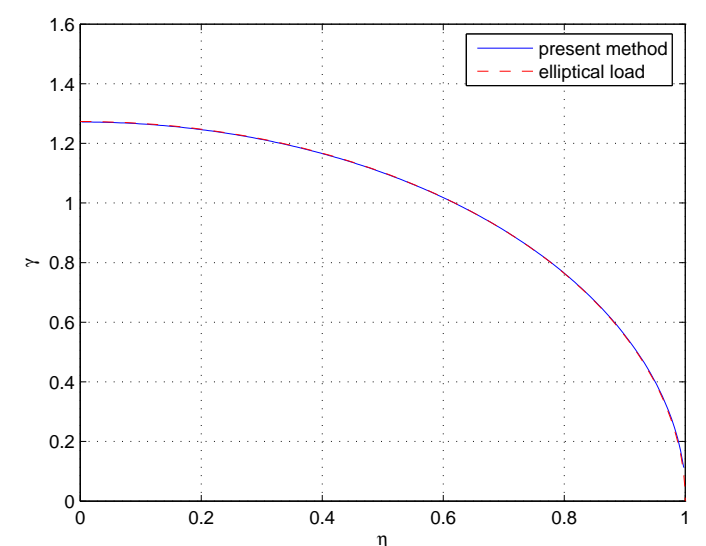

Figure 6. Optimum span-loading $\left(\frac{c_{n} c}{C_{L} \bar{c}}\right)$, resulting in Figure 7. Relation between number of horseshoe vorminimum induced drag for a planar wing.

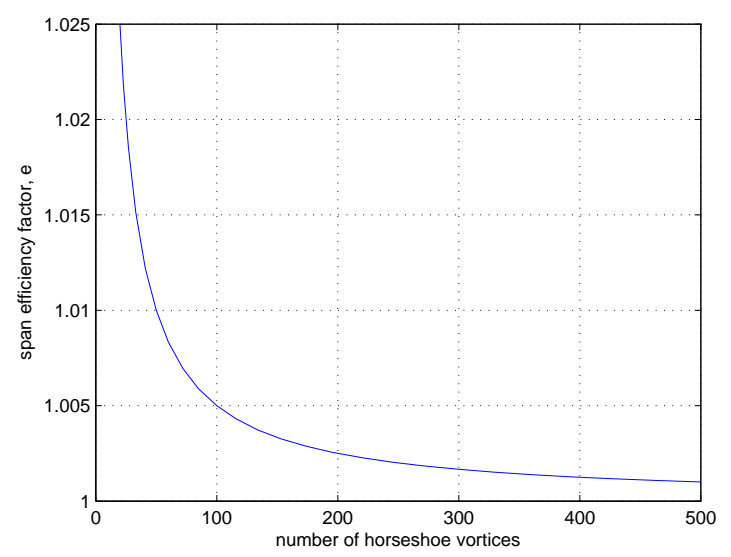
tices and span efficiency factor.

\section{B. Optimum span-loadings}

The span-loadings resulting in minimum induced drag for wingletted and C-wings are plotted in fig. 9 (a), together with the elliptical load. The lift coefficient is 0.5 . The span-loadings of the additional surfaces of the nonplanar wings are plotted as if they are attached to the wing in the horizontal plane. The actual direction of the span-loadings on the different surfaces is given in fig. 8. Both nonplanar wings make use of additional surfaces of $20 \%$ semispan at a $90^{\circ}$ angle. The wing with winglet shows a big increase in load at the wingtip, compensated by a lower load at the root. The load at the wingtip of

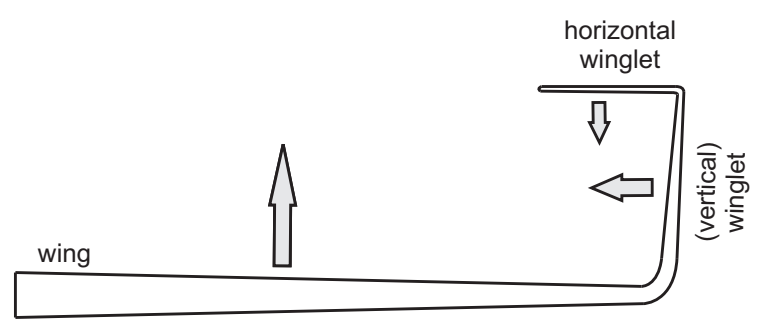

Figure 8. Positive direction of span-loadings on different wing surfaces. the $\mathrm{C}$-wing is even larger, but is compensated by the lower load at the root and by the downward load on the horizontal winglet. The span efficiency factors associated with these wings are 1.22 and 1.25 , equivalent to a reduction in induced drag coefficient of $18 \%$ and $20 \%$ respectively, for wings with the same lift coefficient and aspect ratio. 


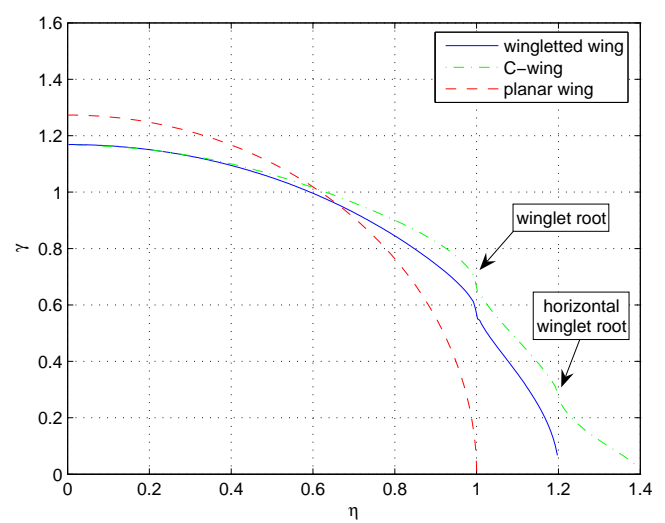

(a) Lift coefficient constraint

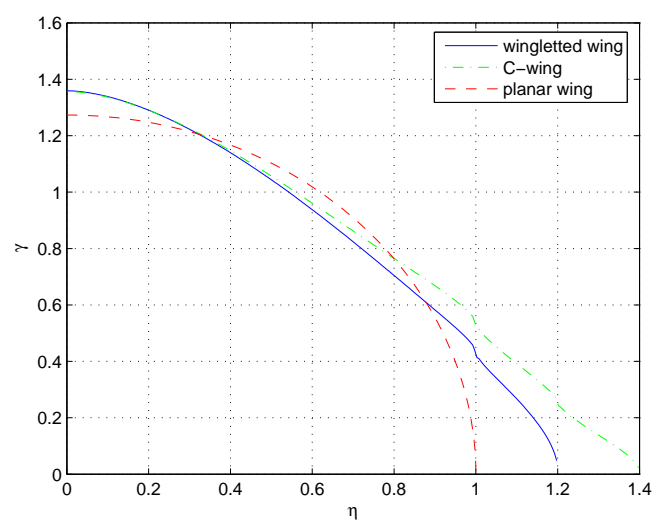

(b) Lift coefficient and WRBM constraint

Figure 9. Optimum span-loading resulting in minimum induced drag for a planar, wingletted, and C-wing.

Figure 9(b) shows the optimum loading that results in minimum induced drag for a wingletted and C-wing with the wing-root bending moment (WRBM) constraint. The loading of the nonplanar wings without WRBM constraint have far more load at the tip region of the wing. Combined with the loading of the winglet the optimum load results in a shift of the center-of-pressure towards the wingtip, increasing wing weight. Therefore the optimum span-loadings calculated with WRBM constraint have more loading at the wing root, and less at the tip. This results in a wing-root bending moment equal to the planar wing, but a drop in span efficiency factor compared to the nonplanar wings analyzed without WRBM constraint. The span efficiency is still significantly higher than a planar wing, namely 1.16 for the wingletted wing and 1.19 for the $\mathrm{C}$-wing, equivalent to a reduction in induced drag coefficient of $14 \%$ and $16 \%$ respectively. The optimum loading resulting in minimum total drag is not significantly different from the loadings resulting in minimum induced drag.

\section{Induced drag coefficient per surface}

The numerical method of this thesis can be used to study the sources of induced drag and the mechanisms of induced drag reduction. Equation (2) can be used to calculate the induced drag components of a surface (wing, winglet, or horizontal winglet) under influence of one of the surfaces. For example, the induced drag component of the wing due to the winglet of a wingletted wing can be calculated using

$$
C_{D_{i} \text { wing, winglet }}=\sum_{i=1}^{N} \sum_{j=N+1}^{N+M} \frac{\left(c_{n} c\right)_{i}}{\bar{c}} \frac{\left(c_{n} c\right)_{j}}{\bar{c}} s A_{i j}
$$

where $N$ is the number of control points on the wing, and $M$ the number of points on the winglet. The results are given in table 1 for four wings; a planar, wingletted, and C-wing without WRBM constraint, and a wingletted wing with WRBM constraint. The lift coefficient is 1 to obtain more convenient induced drag numbers, a negative number indicates an induced drag decrease.

The table contains some interesting results. First consider the wingletted wing without WRBM constraint. The thrust component of the winglet due to the wing is negated by the induced drag created by the winglet itself, as indicated by Munk's third theorem. The winglet of the wingletted wing with WRBM constraint does create some thrust, albeit very little. The main mechanism by which the induced drag is reduced for both wingletted wings is the influence of the winglet on the wing. The results of the C-wing give good insights into the influences of the three surfaces on each other. The sum of the induced drag coefficients of the vertical winglet equals zero. The sum of the induced drag coefficients of the horizontal winglet is negative, indicating a thrust vector is created at the horizontal winglet. The influence of the wing on the horizontal winglet and vice versa is only very small in magnitude. The influence of the winglet of the $\mathrm{C}$-wing on the wing results in a much larger induced drag reduction than for the wingletted wing. The combination 
Table 1. Induced drag contribution per surface due to a surface. $C_{L}=1$

\begin{tabular}{|l|l||c|c|c|c|}
\hline $\begin{array}{l}\text { Induced drag } \\
\text { coefficient }\end{array}$ & $\begin{array}{l}\text { due } \\
\text { to }\end{array}$ & $\begin{array}{c}\text { Planar } \\
\text { wing }\end{array}$ & $\begin{array}{c}\text { wingletted } \\
\text { wing }\end{array}$ & $\begin{array}{c}\text { wingletted wing } \\
\text { WRBM constraint }\end{array}$ & C-wing \\
\hline \hline wing & wing & 0.0318 & 0.0398 & 0.0356 & 0.0454 \\
\hline wing & winglet & & -0.0138 & -0.0079 & -0.0192 \\
\hline wing & h. winglet & & & & -0.0002 \\
\hline winglet & wing & & -0.0137 & -0.0079 & -0.0192 \\
\hline winglet & winglet & & 0.0137 & 0.0078 & 0.0222 \\
\hline winglet & h. winglet & & & & -0.0030 \\
\hline h. winglet & wing & & & & -0.0002 \\
\hline h. winglet & winglet & & & & -0.0030 \\
\hline h. winglet & h. winglet & & & $\mathbf{0 . 0 2 7 6}$ & $\mathbf{0 . 0 2 5 3}$ \\
\hline \multicolumn{2}{|l|}{ total } & $\mathbf{0 . 0 3 1 8}$ & $\mathbf{0 . 0 2 6 0}$ & & 0.0025 \\
\hline
\end{tabular}

of the thrust vector and larger influence of the winglet on the wing only causes a small reduction in total induced drag relative to the wingletted wing, due to the fact that the induced drag coefficient of the wing due to the wing itself on the $\mathrm{C}$-wing is significantly higher than for the wingletted wing.

\section{Drag characteristics}

\section{Wingletted wings}

A larger winglet surface will increase span efficiency and hence decrease induced drag. However, the profile drag will increase. By incorporating the profile drag in the model an optimum winglet height can be found. The profile drag is a function of the profile drag coefficients $\left(c_{d_{0}}\right.$ and $\left.c_{d_{2}}\right)$ and the wing planform. The taper ratios used here are 0.3 for wing and winglet and 1 for the horizontal surface of the C-wing. The aspect ratio of the wing is 10 and the lift coefficient 0.5 . Both profile drag coefficients are assumed to be 0.005 . The planforms of a wingletted wing with an arbitrary winglet height of $20 \%$ of the semi-span, and a C-wing with an arbitrary winglet height of $20 \%$, and horizontal winglet length of $10 \%$ of the semi-span are plotted in fig. 10.

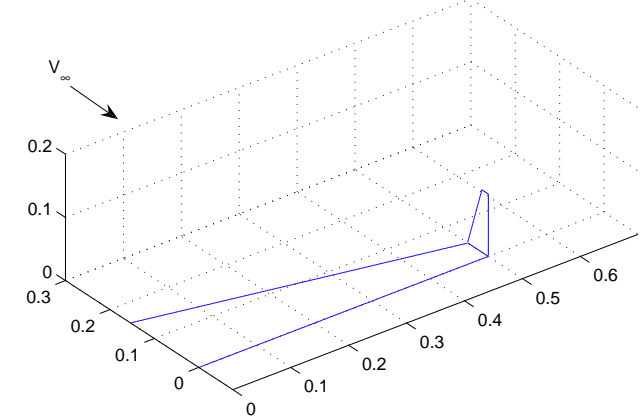

(a) wingletted wing

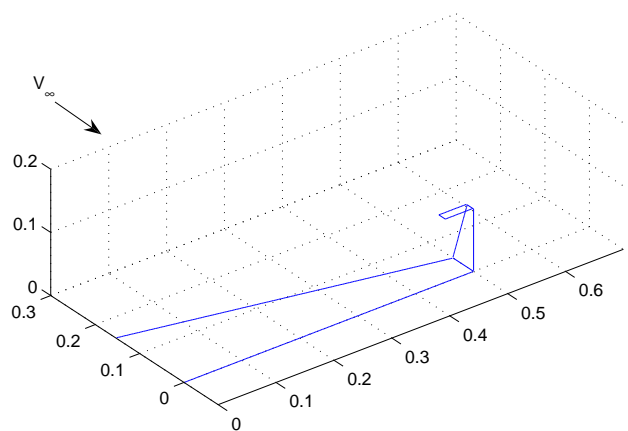

(b) C-wing

Figure 10. Planforms of wingletted and C-wing. $\delta_{\text {winglet }}=0.2$ and $\delta_{\text {c-wing }}=0.1$. Taper ratios of both wing and winglet are 0.3 , taper ratio of horizontal winglet of the C-wing is 1 . Aspect ratio is 10 .

Figure 11(a) shows the difference in drag coefficient between a planar wing and wing with varying winglet 
height. The optimum winglet height is around $75 \%$ of the semi-span ${ }^{c}$ resulting in a decrease in drag coefficient of $11.7 \%$. Beyond that height the increase in profile drag outweighs the decrease in induced drag. The weight of the wingletted wing will be significantly larger than the planar wing due to an increase in wing-root bending moment. By keeping the wing-root bending moment constant, a wing with and without winglet of comparable weight can be analyzed. Figure 11(b) shows the result. The optimal winglet height is now $28 \%$ of the semi-span and the drag decrease is $5.4 \%$. Clearly, when the wingspan is constrained the winglet can offer a significant reduction in drag. The optimum winglet height is still higher than any winglet currently fitted on commercial aircraft. Those winglets are designed taking into account more design requirements than minimizing total drag. Some aircraft designed by Burt Rutan use winglets with heights in the order of magnitude of the optimum height found in this paper.

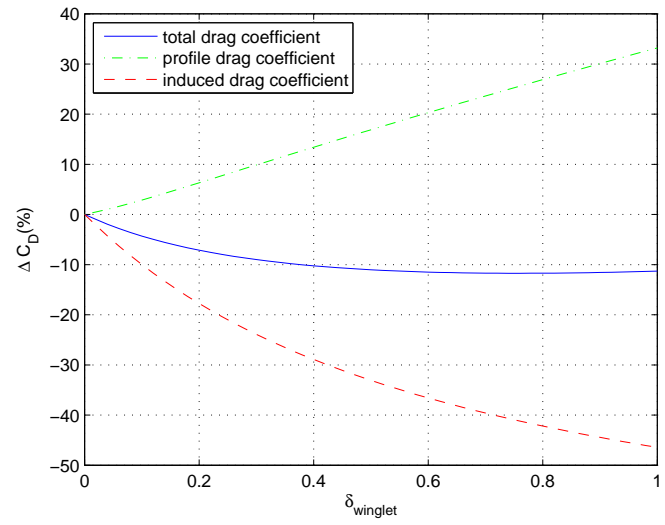

(a) equal span

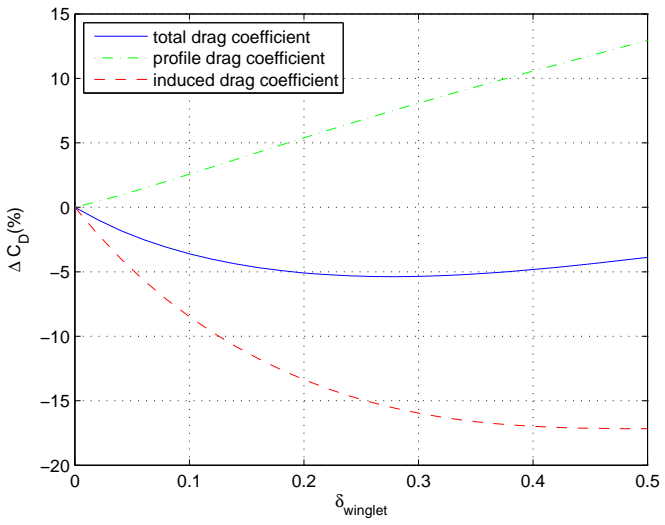

(b) equal span and wing-root banding moment

Figure 11. Difference in induced drag, profile drag, and total drag between a wingletted wing with varying winglet height and a planar wing. The nondimensional winglet height $\delta_{\text {winglet }}$ is relative to the wing semi-span, i.e. $\delta_{\text {winglet }}=1$ indicates a winglet height equal to the wing semi-span.

\section{C-wings}

A comparison of a wing with winglets of $28 \%$ semi-span with a C-wing with equal vertical winglet height and varying horizontal winglet length, and equal wing-root bending moment is presented in fig. 12. Surprisingly, no matter the length of the horizontal winglet the C-wing performs less than the wingletted wing. In other words an optimally loaded wingletted wing with optimum winglet height cannot be improved by adding a horizontal surface to the winglet tip. It is not certain however that a C-wing has the same optimum vertical winglet height as a wingletted wing. Figure 13 shows the total drag reduction of a wingletted wing with varying winglet height compared to a planar wing, similar to fig. 11(b). For every winglet height it also shows the maximum possible drag reduction if a horizontal surface with an optimum length is attached to the winglet tip, creating a $\mathrm{C}$-wing. The optimum horizontal winglet length for a certain vertical winglet height is plotted as well. The C-wing only performs slightly better for winglet heights up to about $25 \%$ of the semi-span. The maximum optimum horizontal winglet length is $3.5 \%$ of the wing semi-span, for winglet heights between $7 \%$ and $15 \%$. The maximum drag reduction relative to a wingletted wing with equal vertical winglet height is only in the order of $0.1 \%$. The C-wings plotted in figure 13 that perform worse than the wingletted wings have an optimum horizontal winglet length equal to zero. No C-wing can be found that performs better than the wingletted wing with optimum winglet height. It can be concluded from these results that it is very questionable if there is any real aerodynamic advantage to the use of C-wings if total drag is considered.

\footnotetext{
${ }^{\mathrm{c}}$ This number seems unrealistically high. This could be caused by the chosen constants of the profile drag assumption and the fact that the assumption does not take reynolds number effects into account.
} 


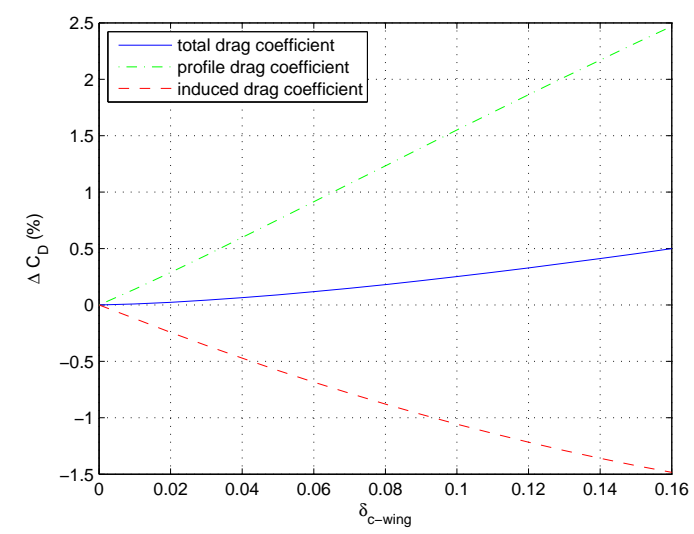

Figure 12. Difference in drag of a $\mathrm{C}$-wing with varying horizontal winglet length and a wingletted wing $\left(\delta_{\text {winglet }}=0.28\right)$, both with the same wing-root bending moment. The nondimensional horizontal winglet length $\delta_{c-\text { wing }}$ is relative to the wing semi-span, i.e. $\delta_{c-w i n g}=1$ indicates a horizontal winglet length equal to the wing semi-span.

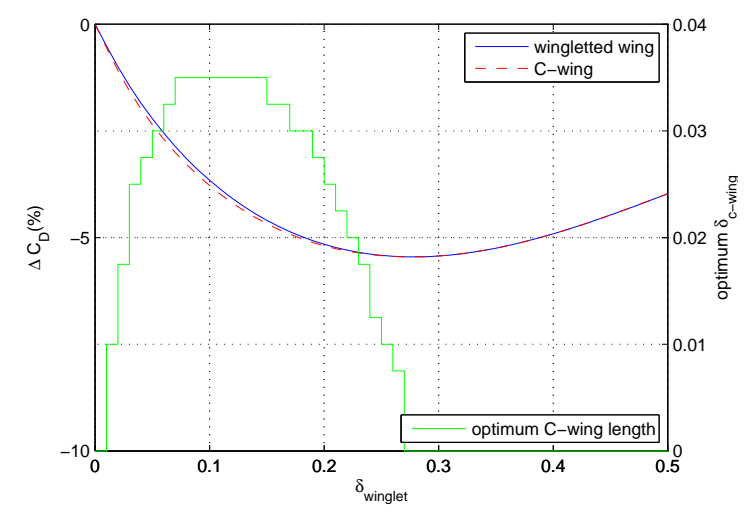

Figure 13. Total drag reduction of a wingletted wing with varying winglet height and constant wing-root bending moment compared to the best possible C-wing configuration.

\section{Extended wing vs. wingletted wing}

The reduction of drag due to a winglet can also be achieved by increasing the wingspan of a planar wing. For a fair comparison the wingletted and extended wings analyzed here have the same wing-root bending moment and lift as an unextended elliptically loaded planar base wing. The lift of the extended planar wing can be kept constant in two ways, assuming a constant dynamic pressure. The lift coefficient and wing area can be kept constant for both wings, or the wing area of the extended wing can be increased, and the lift coefficient decreased such that the product of both parameters, $C_{L} S$, is constant.

First the method of keeping the wing area constant is used. In fig. 14(a) the wingtip extension and associated aspect ratio needed to achieve the same drag reduction as wingletted wings with varying winglet heights are plotted. All wings analyzed have the same wing-root bending moment and lift as the optimally loaded planar base wing with aspect ratio 10. The needed tip extensions to match the drag reduction of the wingletted wings are significantly smaller than the winglet heights. A span extension of $6.7 \%$ of the semi-span is needed to achieve the same drag reduction as a wingletted wing with optimum winglet height of $28 \%$ of the wing semi-span. The aspect ratios are still acceptable compared to the base value of 10 . Figure 15(a) shows the planforms of a wingletted wing with optimal winglet height and an extended planar wing with the same drag.

The second method gives somewhat different results. Because the wing area is altered when using the second method it is not sufficient to compare drag coefficients. Drag is equal to $C_{D} q_{\infty} S$, so for a certain 


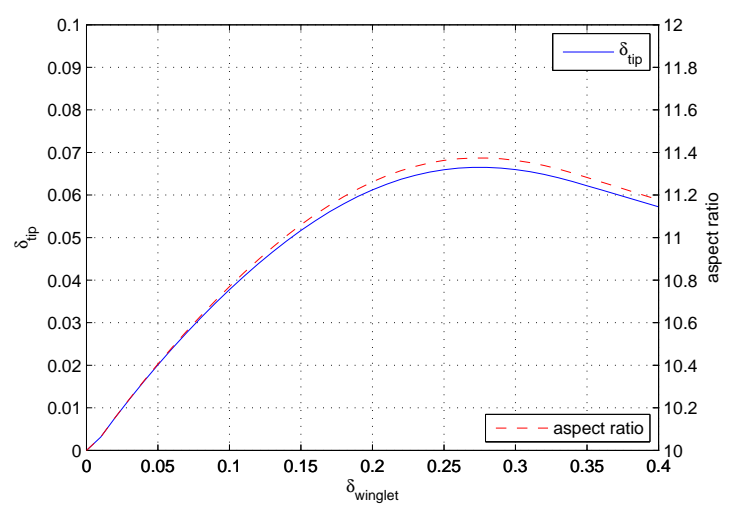

(a) constant wing area

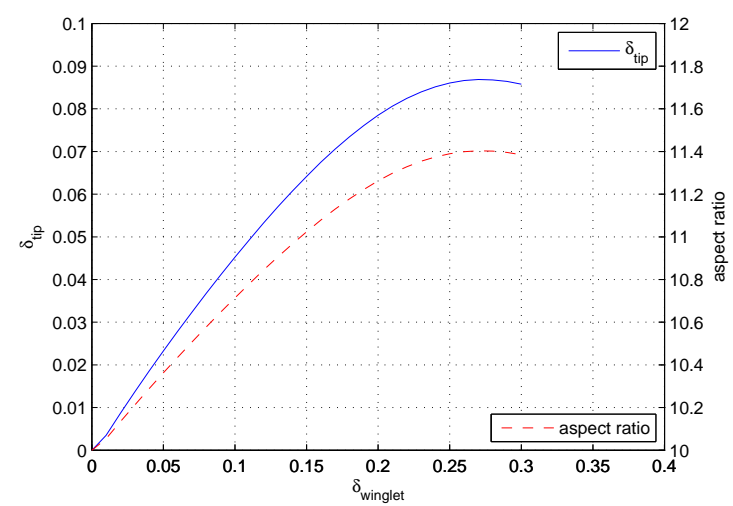

(b) constant $C_{L} S$

Figure 14. Wingtip extension $\delta_{\text {tip }}$ and associated aspect ratio needed to achieve the same drag reduction, relative to an unextended planar wing, as a wingletted wing with varying winglet height. The nondimensional wingtip extension $\delta_{t i p}$ is relative to the wing semi-span, i.e. $\delta_{t i p}=1$ indicates a wingtip extension equal to the wing semi-span.

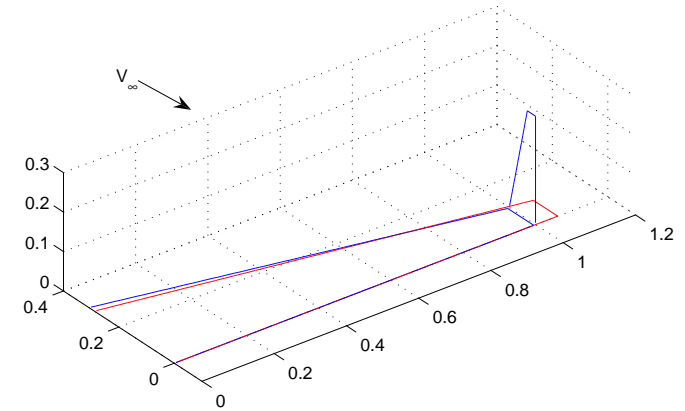

(a) constant wing area

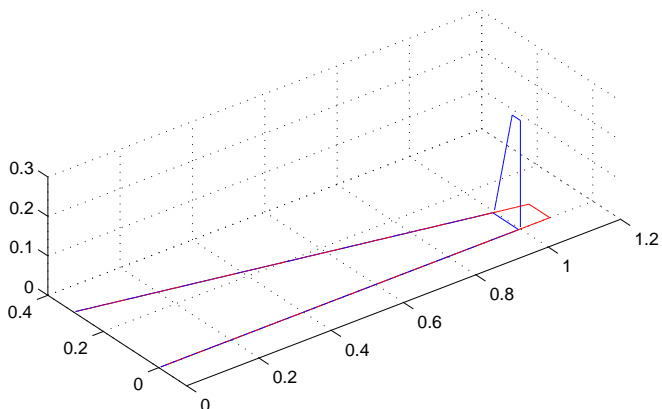

(b) constant $C_{L} S$

Figure 15. Planform of a wingletted wing with optimum winglet height and an extended wing having the same wing-root bending moment, lift and drag.

dynamic pressure $C_{D} S$ needs to be equal for the compared wings to have equal drag. The tip extension is restricted to a maximum because of the decreasing taper ratio. As can be seen from fig. 14(b) the needed wingtip extensions to achieve the same drag as wingletted wings are larger than for the first method. The needed span extension to achieve the same drag reduction as a wingletted wing with optimum winglet height is $8.7 \%$. The corresponding aspect ratios are about the same as for the first method however. Figure 15(b) shows the planforms of both wings.

It can be concluded that for every wingletted wing an extended wing with equal performance can be found. The wing does not have to be extended significantly. The wing can be extended further to perform even better than the wingletted wing, although the increasing aspect ratio introduces other problems for transport aircraft.

\section{Extended wings with winglets}

Figure 16 shows the drag reduction of extended wings relative to an unextended base wing as function of tip extension for both methods of keeping the lift constant. With both methods a drag reduction can be obtained larger than possible with a wingletted wing with optimum winglet height. However, an extended 
wing can be fitted with a winglet as well, without increasing the span. Therefore, fig. 16 shows the influence of a vertical winglet of optimum height on the performance of the extended wing. For every tip extension analyzed the optimum winglet height for that particular extended wing is found and its drag performance plotted. This is done for both methods of keeping the lift constant. All wings analyzed have the same wing-root bending moment and lift as a base planar wing with aspect ratio 10. The optimum winglet height is relative to the base wing of unit span. In other words, a winglet height of 0.20 equals $20 \%$ of the semi-span of the unextended base wing.

The plots contain quite some information. First consider the method of keeping wing area constant, fig. 16(a). Some of the previous results can be found in this plot as well. Relative to the base wing an unextended wingletted wing with $28 \%$ semi-span winglet height achieves a drag reduction of a bit more than $5 \%$, as we have seen in fig. 11(b). That performance can also be achieved by an extended wing with approximately $7 \%$ semi-span extension as seen before. The plot also contains new information. Up until $15 \%$ semi-span tip extension wingletted wings of equal span can be found that perform better than the extended planar wings. The best possible performance is achieved by an extended planar wing with a tip extension of around $22 \%$ of the semi-span. The total reduction relative to the base wing is $8 \%$. That performance can not be improved by adding a winglet.

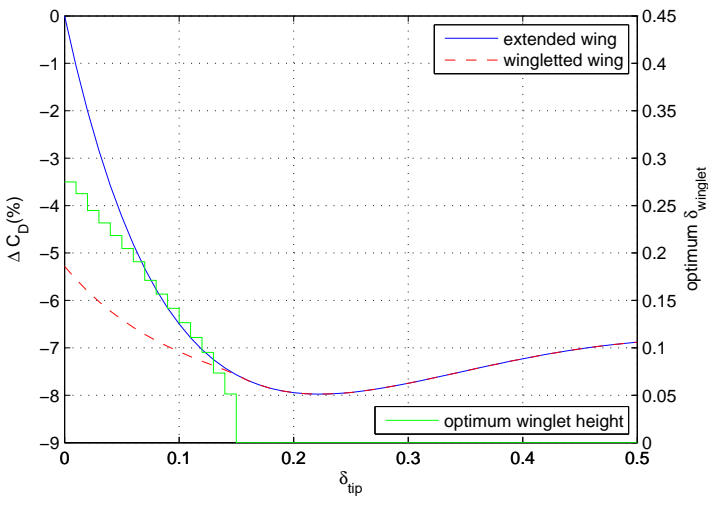

(a) constant wing area

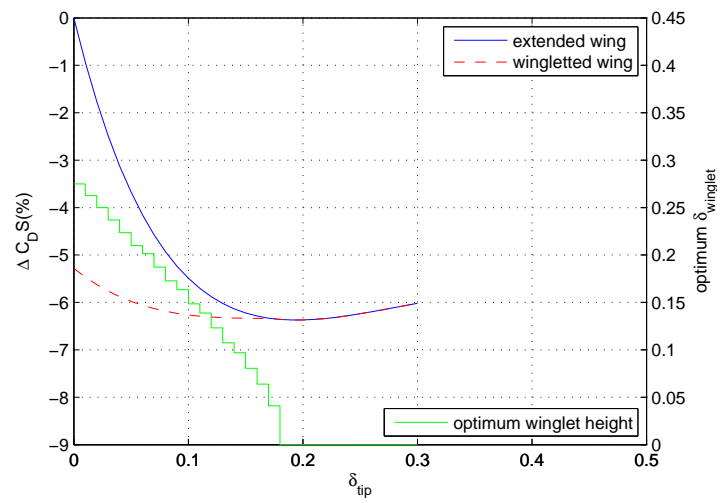

(b) constant $C_{L} S$

Figure 16. Difference in total drag between an extended planar wing and a planar wing with aspect ratio 10. Maximum possible drag reduction for optimum winglet height.

Figure 16(b) shows the performance of extended planar and wingletted wings for the method of keeping $C_{L} S$ constant. Here the reduction in $C_{D} S$ is compared for all wings. The drag reduction is smaller than achieved by the first method. The wingletted wing performs better up until $18 \%$ semi-span tip extension. The best performance for an extended wing can also be reached by a wingletted wing with a smaller span. The best extended wing has a tip extension of almost $20 \%$ semi-span and a drag reduction of $6.4 \%$. The same reduction can be achieved with a $13 \%$ extended wingletted wing with $11 \%$ semi-span winglet height. No wing performs better than the best wing from fig. 16(a).

Summarizing figs. 16(a) and 16(b), it is clear that the best performance can be reached using an extended planar wing. An disadvantage of extending a wing without changing the wing area significantly is an increase in aspect ratio. Figure 17 shows the aspect ratio for the extended wings, with a base wing of aspect ratio 10. Clearly the aspect ratio becomes too large at some point. For the best performing wing, the $22 \%$ extended planar wing using the method of keeping the wing area constant, the aspect ratio is around 15.

For many aircraft there are constraints to the aspect ratio. For subsonic transport aircraft the aspect ratio ranges form about 6 (McDonald Douglas DC-10) to 12 (Fokker 50). The deflection along a high aspect ratio wing tends to be much higher than for one of low aspect ratio, which increases the chance of flutter. Low aspect ratio wings tend to be more naturally stable, resulting in handling advantages, especially at low speeds. Furthermore, low aspect ratio wings have a greater useful internal volume, which can be used to 


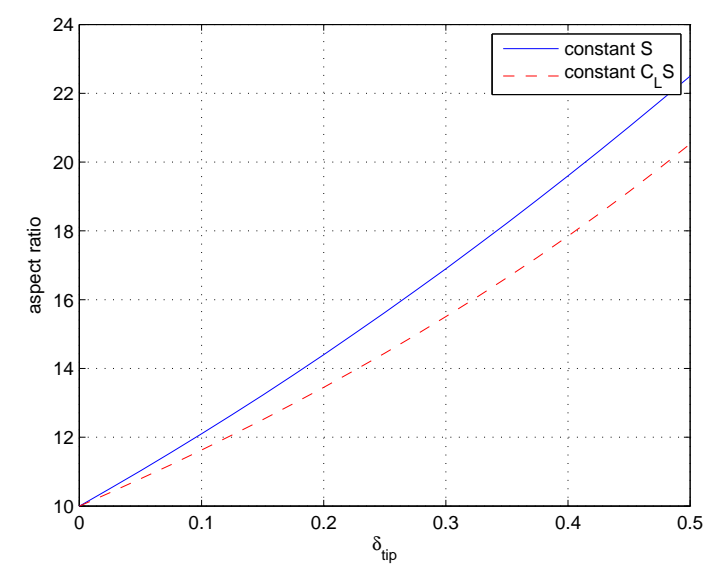

Figure 17. Aspect ratio increase as function of span extension for both methods of keeping lift constant.

house the fuel tanks, landing gear, and other systems. Because of this restriction in aspect ratio, winglets have definitive advantages over wingtip extensions. Although the maximum drag decrease relative to a base wing can be achieved with an extended wing, the wingletted wing is capable of higher drag reductions if there are constraints to the aspect ratio. Therefore, it can be concluded that there are justifications for winglets when the span is constraint, but also justifications for winglets opposed to span extensions only, because of constraints to aspect ratio.

\section{Conclusions and recommendations}

The method presented in this paper can be used to get a global idea of the performance of several planar and nonplanar wing configurations. Although the results are approximations of the actual performance of the wings, the method can be used to quickly assess how different configurations compare to each other and which trends they follow when surface sizes are altered and constraints imposed.

An optimally loaded nonplanar wing produces less induced drag than an elliptically loaded planar wing. If profile drag is incorporated an optimum winglet height of a wingletted wing of $75 \%$ of the wing semi-span is found. The drag is reduced by $11.7 \%$ relative to the elliptically loaded planar wing, but the wing-root bending moment is increased. A wingletted wing with the wing-root bending moment of an optimally loaded planar wing has an optimum winglet height of $28 \%$ of the semi-span. The drag reduction is $5.4 \%$. It can be concluded that winglets provide a drag reduction when the wingspan is constrained.

C-wings that perform marginally better than wingletted wings with the same wing-root bending moment can be found for vertical winglet heights up to $25 \%$ of the semi-span. The maximum drag reduction relative to a wingletted wing with equal winglet height is only in the order of $0.1 \%$. There is no C-wing that performs better than the wingletted wing with optimal winglet height. Therefore it is concluded that there is no real aerodynamic performance advantage of the $\mathrm{C}$-wing compared to the wingletted wing.

The drag can also be reduced by increasing the wingspan of a planar wing but keeping the wing-root bending moment constant. The maximum drag reduction that can be achieved by an extended wing is $8.0 \%$ for a tip extension of $22 \%$ of the semi-span. The aspect ratio of such a wing is 15 . The extended planar wing can also be fitted with a winglet. No extended wingletted wing has a higher drag reduction than the $22 \%$ extended planar wing. For smaller tip extensions, and hence lower aspect ratios, winglets fitted on extended wings do provide an additional drag reduction relative to planar wings with the same span. It can therefore be concluded that if there are constraints to the aspect ratio winglets can be used to reduce induced drag. Subsonic transport aircraft aspect ratios range form 6 to 12, indicating there are constraints to aspect ratio.

The recommendations for future work on this topic fall into three categories, namely related to the pro- 
file drag estimation, the wing weight estimation, and the optimization goal. The profile drag estimation used in this thesis was relatively simple. The approximation can be improved by incorporating the Reynolds number effect due to differences in chord length between the wing and the winglet. The Reynolds number of the winglet is lower than the wing, resulting in a larger influence of the profile drag.

The weight estimation can be improved. The weight of the additional surface can be incorporated in the model. The additional weight also causes a decrease in wing-root bending moment, decreasing the wing weight. This relief factor can be incorporated in the model as well. This thesis found span-loadings optimized for minimum induced and total drag. The aerodynamic optimum resulting in minimum drag is not necessarily the most preferable optimum. Using the lift-to-drag ratio and the ratio of gross weight to empty weight the span-loading can be optimized for maximum range. Finally, the optimization method could include variable winglet cant, to find the optimum winglet cant angle.

\section{Appendix: The Biot-Savart law and the Kutta-Joukowski theorem}

The Biot-Savart law can be used to relate the induced velocity to the circulation strength and distribution. ${ }^{4}$ The law indicates that the induced velocity at a point is proportional to the circulation strength at another point and inversely proportional to the distance between the points. The law is given by

$$
\mathbf{d V}=\frac{\Gamma}{4 \pi} \frac{\mathbf{d l} \quad \mathbf{x} \quad \mathbf{r}}{|\mathbf{r}|^{3}}
$$

The Kutta-Joukowski theorem gives the relation between circulation and span-load distribution. ${ }^{2}$ The theorem is given by

$$
\frac{2 \Gamma}{V_{\infty} \bar{c}}=\frac{c_{n} c}{\bar{c}}
$$

\section{References}

\footnotetext{
${ }^{1}$ Flechner, S.G., Jacobs, P.F., and Whitcomb, R.T., A High Subsonic Speed Wind-Tunnel Investigation of Winglets on a Representative Second-Generation Jet Transport Wing, NASA, TN D-8264, July 1976

${ }^{2}$ Blackwell Jr., J.A., Numerical Method to Calculate the Induced Drag or Optimum Loading for Arbitrary Non-Planar Aircraft, NASA SP-405, May 1976.

${ }^{3}$ Kroo, I.M., Design and Analysis of Optimally-Loaded Lifting Systems, AIAA-84-2507, October 1984.

${ }^{4}$ Anderson Jr., J.D., Fundamentals of Aerodynamics, McGraw-Hill, New York, 2001.
}

\section{Necrology}

On Friday the 19th of October the co-author of this paper, Ronald Slingerland (46), died in an accident during which his plane crashed into another small aircraft. The plane lost a section of its tail and was damaged beyond recovery. He was flying the plane together with his colleague Poppe de Lange (70), who also did not survive the accident. They both will be missed.

Ronald gave lectures on preliminary design of aircraft and ran design exercises, alongside a lot of other teaching and research activities. His extraordinary lectures were flavored with his practical knowledge of flying. He would combine his wealth of experience from working as a member of the team of preliminary designers at Fokker with an almost encyclopedic knowledge of aircraft.

For me Ronald has been an exceptional tutor during the year I worked on my final thesis, which formed the basis for this paper. I have learned a lot from Ronald. I always liked discussing my progress with him. During these meetings he always had enough ideas on how to continue the study. His enthusiasm about numerous aircraft related topics was very inspirational and motivational.

Joram Verstraeten, December 14, $200 \%$.

Also on behalf of the Section Design and Operation of Aircraft and Rotorcraft of the Faculty of Aerospace Engineering of the Technological University Delft. 